\title{
Parkinsonian phenotype in Machado-Joseph disease (MJD/SCA3): a two-case report
}

\author{
Conceição Bettencourt ${ }^{1,2,3,4^{*}}$, Cristina Santos ${ }^{5}$, Paula Coutinho ${ }^{3,6}$, Patrizia Rizzu ${ }^{7}$, João Vasconcelos ${ }^{8}$, Teresa Kay ${ }^{9}$, \\ Teresa Cymbron ${ }^{1,2,3}$, Mafalda Raposo ${ }^{1,2}$, Peter Heutink ${ }^{7}$ and Manuela Lima ${ }^{1,2,3}$
}

\begin{abstract}
Background: Machado-Joseph disease (MJD), or spinocerebellar ataxia type 3 (SCA3), is an autosomal dominant neurodegenerative disorder of late onset, which is caused by a CAG repeat expansion in the coding region of the ATXN3 gene. This disease presents clinical heterogeneity, which cannot be completely explained by the size of the repeat tract. MJD presents extrapyramidal motor signs, namely Parkinsonism, more frequently than the other subtypes of autosomal dominant cerebellar ataxias. Although Parkinsonism seems to segregate within MJD families, only a few MJD patients develop parkinsonian features and, therefore, the clinical and genetic aspects of these rare presentations remain poorly investigated. The main goal of this work was to describe two MJD patients displaying the parkinsonian triad (tremor, bradykinesia and rigidity), namely on what concerns genetic variation in Parkinson's disease (PD) associated loci (PARK2, LRRK2, PINK1, DJ-1, SNCA, MAPT, APOE, and mtDNA tRNA ${ }^{\text {Gln }}$ T4336C).
\end{abstract}

Case presentation: Patient 1 is a 40 year-old female (onset at 30 years of age), initially with a pure parkinsonian phenotype (similar to the phenotype previously reported for her mother). Patient 2 is a 38 year-old male (onset at 33 years of age), presenting an ataxic phenotype with parkinsonian features (not seen either in other affected siblings or in his father). Both patients presented an expanded ATXN3 allele with 72 CAG repeats. No PD mutations were found in the analyzed loci. However, allelic variants previously associated with PD were observed in DJ-1 and APOE genes, for both patients.

Conclusions: The present report adds clinical and genetic information on this particular and rare MJD presentation, and raises the hypothesis that DJ-1 and APOE polymorphisms may confer susceptibility to the parkinsonian phenotype in MJD.

\section{Background}

Autosomal dominant cerebellar ataxias (ADCA) constitute a heterogeneous group of neurodegenerative disorders, which involve, besides other systems, the extrapyramidal system in a highly variable manner. Within this group is Machado-Joseph disease (MJD; MIM \#109150), also known as spinocerebellar ataxia type 3 (SCA3), that presents extrapyramidal motor signs (EPS) more frequently than the other subtypes of ADCA [1]. Even within MJD, the EPS may vary, sometimes with marked dystonic postures, others with isolated parkinsonian features or even, though rarely, with the parkinsonian triad (resting tremor, bradykinesia and

\footnotetext{
* Correspondence: mcbettencourt@uac.pt

${ }^{1}$ Center of Research in Natural Resources (CIRN), University of the Azores,

Ponta Delgada, Portugal

Full list of author information is available at the end of the article
}

rigidity) [2]. Although the causative mutation of MJD is known to be an expansion of a CAG repeat motif (consensually more than 52 repeats) in the coding region of the ATXN3 gene [3], the size of the of the repetitive tract does not completely explain the clinical heterogeneity observed in this disorder, namely concerning the presence of EPS.

There are only a few reports of a Parkinson's disease (PD)-like phenotype in molecularly confirmed MJD patients [4-6], and thus this particular MJD phenotype remains poorly documented, namely from the genetic point of view. The cases reported in the literature showed an initial phenotype indistinguishable from PD and a levodopa positive response. Only after several years of progression the characteristic features of MJD, namely cerebellar signs, were observed. The parkinsonian phenotype has been suggested to be more common
C Biomed Central

(c) 2011 Bettencourt et al; licensee BioMed Central Ltd. This is an Open Access article distributed under the terms of the Creative Commons Attribution License (http://creativecommons.org/licenses/by/2.0), which permits unrestricted use, distribution, and reproduction in any medium, provided the original work is properly cited. 
in MJD patients of African descent, although rare in those of European origin [7].

MJD phenotypes with EPS, particularly those with a PD-like phenotype, may result from epistatic effects of variants in other loci. As primary candidates are $P D$ associated loci, namely PARK2, LRRK2, PINK1, DJ-1, SNCA, MAPT, and APOE (e.g. [8-10]). Variation in mitochondrial DNA (mtDNA) has also been shown to have an impact on neurodegenerative diseases' phenotype, and the $t R N A^{G l n} \mathrm{~T} 4336 \mathrm{C}$ mutation was previously associated with Alzheimer's disease (AD) and PD [11]. The main goal of this work was to describe two unrelated MJD patients displaying the parkinsonian triad, for which the genetic variation (mutations and/or polymorphisms) in PD associated loci was investigated.

\section{Case Presentation}

Out of a series of 70 molecularly confirmed MJD patients from the Azores Islands (Portugal), from whom DNA samples were available (extracted from blood samples, which were collected after obtaining written informed consent), two patients presenting the parkinsonian triad, and belonging to distinct MJD families (one from São Miguel Island and other from Graciosa Island), were identified.

\section{Patient 1}

Patient 1 is a 40 year-old female patient (Figure 1; III-4). At the age of 30 years (Table 1), she noticed slowness of movements. At examination, she had a poor mimic and marked bradykinesia. She responded well to L-dopa, which she maintained for 8 years. At this time she was hospitalized because of neurological aggravation and depression. She presented, besides a prominent parkinsonian syndrome with frequent on-off phenomena, cerebellar dysarthria and general incoordination, axial and upper limbs dystonia, upwards gaze limitation with upwards gaze nystagmus, generalized hyperreflexia and bilateral Babinski sign, as well as marked gait ataxia.

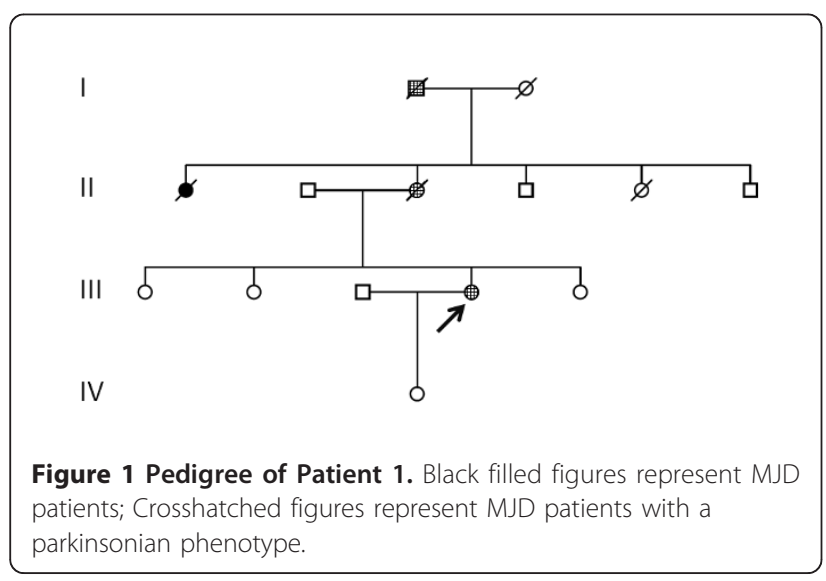

Table 1 Characteristics of Patient 1 and Patient 2

\begin{tabular}{|c|c|c|}
\hline Characteristics & Patient 1 & Patient 2 \\
\hline Age at Onset & 30 & 33 \\
\hline Onset Mode & Pure PD signs & $\begin{array}{c}\text { PD plus cerebellar } \\
\text { signs? }\end{array}$ \\
\hline $\begin{array}{l}\text { Family history for PD } \\
\text { features }\end{array}$ & $\begin{array}{l}\text { Mother and } \\
\text { grandfather }\end{array}$ & NP \\
\hline \multicolumn{3}{|l|}{$\begin{array}{l}\text { ATXN3 (CAG)n tract } \\
\text { length }\end{array}$} \\
\hline Normal Allele & 14 & 29 \\
\hline Expanded Allele & 72 & 72 \\
\hline PARK2 Gene Mutations & NP & NP \\
\hline LRRK2 Gene Mutations & NP & NP \\
\hline PINK1 Gene Mutations & NP & NP \\
\hline \multicolumn{3}{|l|}{ DJ-1 Gene } \\
\hline Mutations & NP & NP \\
\hline \multicolumn{3}{|l|}{ Polymorphisms } \\
\hline g.168_185del & Del/Del & Ins/Del \\
\hline rs7517357 & $\mathrm{T} / \mathrm{T}$ & $C / T$ \\
\hline rs2641116 & $\mathrm{G} / \mathrm{G}$ & $\mathrm{T} / \mathrm{G}$ \\
\hline rs56327722 & A/A & $\mathrm{G} / \mathrm{A}$ \\
\hline \multicolumn{3}{|l|}{ SNCA Gene } \\
\hline REP1 & $261 / 261$ & $261 / 261$ \\
\hline \multicolumn{3}{|l|}{ MAPT Gene } \\
\hline rs242557 & $A / G$ & $\mathrm{G} / \mathrm{G}$ \\
\hline Haplotype & $\mathrm{H} 1 / \mathrm{H} 2$ & $\mathrm{H} 2 / \mathrm{H} 2$ \\
\hline \multicolumn{3}{|l|}{ APOE Gene } \\
\hline genotype & $\varepsilon 2 / \varepsilon 3$ & $\varepsilon 2 / \varepsilon 3$ \\
\hline \multicolumn{3}{|l|}{ mtDNA } \\
\hline T4336C mutation & NP & NP \\
\hline Haplogroup & $\mathrm{H}$ & $\mathrm{H}$ \\
\hline
\end{tabular}

NP - Not present

Her mother (Figure 1; II-3) also had exhibited a parkinsonian phenotype. By the age of 34 , she noticed difficulty in walking and in the fine movements of the hands. First examined at 36, she had bradykinesia, including amimia, bilateral hypertonia, without tremor, nor incoordination. The gait was purely parkinsonian, with small steps and no balance of the arms. She responded well to L-dopa, reaching a normal neurological examination under $300 \mathrm{mg}+75 \mathrm{mg}$ of the inhibitor. Examined 12 years later, she was still under L-dopa treatment. Besides her parkinsonian syndrome and extreme diskynesias, she had a deep depression, a moderate gait and lower limbs' ataxia, cerebellar dysarthria, and marked upwards gaze limitation. The maternal grandfather of Patient 1 (Figure 1; I-1) had an onset at 63 years of age with slowly progressive gait ataxia, followed by dysarthria, diplopia and dysphagia. Examined the first time with 8 years of evolution, he had upwards gaze limitation and horizontal squint, moderate peroneal atrophy with generalized arreflexia, plantars in flexion, slight dysmetria in the upper limbs, marked dysmetria 
in the lower limbs and ataxic gait possible with unilateral support. Four years later mild Parkinson's signs were observed, with resting tremor in the upper limbs and bilateral rigidity. He died two years later aged 77 years.

\section{Patient 2}

Patient 2 is a 38 year-old male patient (Figure 2: II-16). He reported complaints of left hand's tremor since he was 33 years old. In neurological examination at the age of 35 years, he presented slight tremor of the left hand and of the L-lower limb. There was a cog-wheel rigidity of the left side, slight ataxia, hyperreflexia and right Babinski sign. The EPS responded consistently to Ldopa. His MRI was normal. His father (Figure 2: I-1) was only observed after 18 years of disease progression (reported onset at 42 years old), but did not present EPS. Furthermore, none of the remaining affected siblings (Figure 2: II-4, II-9, and II-12) present parkinsonian features.

\section{Molecular analysis}

The ATXN3 (CAG) ${ }_{\mathrm{n}}$ tract size was determined as previously described [12]. All the exons and exon-introns boundaries of PARK2, LRRK2, PINK1 and DJ-1 genes were amplified by PCR. The resulting PCR products were purified by Exo-SAP treatment (GE Healthcare) and sequenced using the BigDye ${ }^{\circledR}$ Terminator v3.1 Cycle Sequencing Kit (Applied Biosystems). Multiplex Ligation-Dependent Probe Amplification (MLPA) was used, according to Djarmati et al. [13], to search for large deletions or duplications in PARK2, PINK1 and $D J-1$. The SNCA REP1 allele-length variants were genotyped as previously described [9]. In MAPT locus, a SNP (rs242557) was genotyped by a custom Taqman assay according to the manufacturer's specifications, and its genotype was used to infer $M A P T$ haplotypes. The $A P O E$ genotypes were determined according to Bettencourt et al. [14]. The mtDNA haplogroup was established as previously described by Santos et al. [15], and the region encompassing the $\mathrm{T} 4336 \mathrm{C}$ mutation was amplified by PCR, according to Ramos et al. [16]. PCR products were purified using the JETQUICK PCR Purification Spin Kit (Genomed) and sequenced, using the BigDye $^{\circledR}$ Terminator v3.1 Cycle Sequencing Kit (Applied Biosystems), according to the manufacturer's specifications.

Both patients presented 72 CAG repeats in their expanded ATXN3 allele (Table 1), which corresponds to the mode for the expanded alleles in the Azorean MJD series [17]. In PARK2, LRRK2, PINK1, DJ-1 and mtDNA $t R N A^{G l n}$, no known pathogenic mutations were detected in the analyzed regions (Table 1). Several polymorphisms were found at the $D J-1$ gene (Table 1 ). Results for the SNCA REP1, MAPT and APOE loci, as well as for the mtDNA haplogroup, are shown in Table 1.

Although MJD presents EPS more frequently than the other ADCAs, the manifestation of the parkinsonian triad is rare, being present in less than $3 \%$ of the analyzed MJD series. Even though the two studied cases are distinct, the grandfather-mother-daughter transmission in the family of Patient 1 , and the heterogeneity presented by the family of Patient 2, suggests a supporting genetic background, e.g. modifier gene(s).

Mutations in the PARK2 gene have been described as the most frequent in the cases of early onset PD [18]. However, none of the studied patients presented mutations in this gene. Similarly, no mutations were identified in LRRK2, PINK1 and DJ-1 genes, or in position 4336 of mtDNA.

Given the fact that both patients belong to a typically European mtDNA haplogroup [15], the hypothesis of an African background, in which the parkinsonian phenotype seems more common [7], was not supported, at least in terms of maternal origin.

Association studies have shown that certain alleles of the SNCA REP1 locus, as well as the presence of two copies of MAPT H1, increase the risk of PD (e.g. [9,10]). In the patients analyzed, however, the homozygousity for the 261 allele (the commonest among Caucasians [9]), and the presence of at least one MAPT H2 was confirmed.

Although previous studies $[19,20]$ failed to find an association between $D J-1$ g.168_185del polymorphism

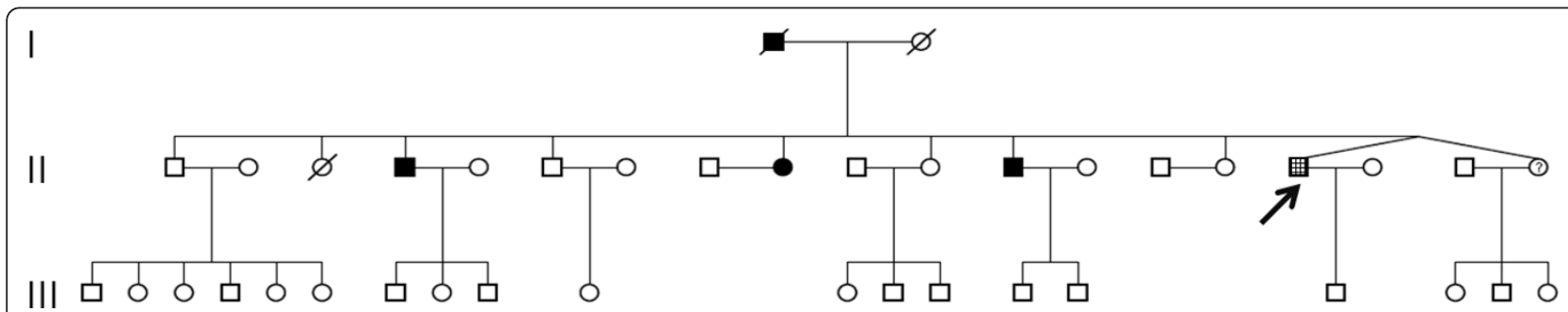

Figure 2 Pedigree of Patient 2. Black filled figures represent MJD patients; Crosshatched figures represent MJD patients with a parkinsonian phenotype. 
and PD, De Marco et al. [21], using a larger series of PD patients, have reported that several $D J-1$ polymorphisms, including those observed in the present study and reported in Table 1, are significantly associated with PD.

The $A P O E \varepsilon 2$ has been associated with increased risk of sporadic PD [8], and with an earlier onset of PD (e.g. [22]). The studied patients presented both the APOE $\varepsilon 2 /$ $\varepsilon 3$ genotype.

In non-Parkinsonian patients $(\mathrm{N}=55)$ from the Azorean MJD series (data not shown), the DJ-1 g.168_185del was found in $23 \%$ of the alleles, not differing from the frequency of this deletion in other non-Parkinsonian Caucasian populations studied previously (e.g. [19-21]). The APOE $\varepsilon 2$ allele was present in only $4 \%$ of the alleles, which corresponds to a lower frequency than the one previously reported for this allele in the general Azorean population [14]. Besides the two Parkinsonian MJD patients studied here, only 2 additional Azorean patients (non-Parkinsonian) carry both the DJ-1 g.168_185del and the APOE $\varepsilon 2$ allele.

\section{Conclusions}

The present report, in these two MJD patients, adds information on this rare phenotype, by allowing a deeper knowledge of the clinical and genetic variation present in such particular cases. Analysis of both pedigrees supports a genetic background influence. Although we cannot conclude on the presence of associations by studying only two Parkinsonian patients, the present results are in agreement with previous studies on Parkinson's disease. The implication of these findings, on what concerns a possible epistatic effect of the $D J-1$ g.168_185del and the APOE $\varepsilon 2$ allele on the MJD phenotype deserves to be tested, using an appropriate study design, namely on what concerns adequate sized parkinsonian MJD series (presently unavailable, to our knowledge).

\section{Consent}

Written consent was obtained from both patients for the publication of this case report. A copy of written consent is available for review by the Editor-in-Chief of this journal.

\footnotetext{
Acknowledgements

This work was supported by "PRI-DMJ" (funded by Regional Government of the Azores), and "Transcriptional variation of the ATXN3 gene as modulator of the clinical heterogeneity in Machado-Joseph disease (MJD)" (PIC/IC/ 83074/2007, funded by "Fundação para a Ciência e a Tecnologia" - FCT). C.B. [SFRH/BPD/63121/2009] and T.C. [SFRH/BPD/38659/2007] are postdoctoral fellows from FCT.
}

\section{Author details}

${ }^{1}$ Center of Research in Natural Resources (CIRN), University of the Azores, Ponta Delgada, Portugal. ${ }^{2}$ Department of Biology, University of the Azores, Ponta Delgada, Portugal. ${ }^{3}$ Institute for Molecular and Cell Biology (IBMC),
University of Porto, Porto, Portugal. ${ }^{4}$ Laboratorio de Biología Molecular, Instituto de Enfermedades Neurológicas, Fundación Socio-Sanitaria de Castilla-La Mancha, Guadalajara, Spain. ${ }^{5}$ Unitat Antropologia Biològica, Dep. Biologia Animal, Biologia Vegetal i Ecologia, Universitat Autònoma de Barcelona, Bellaterra (Barcelona), Spain. ${ }^{6}$ Department of Neurology, Hospital São Sebastião, Feira, Portugal. 'Section of Medical Genomics, Department of Clinical Genetics, VU University Medical Center, Amsterdam, the Netherlands. ${ }^{8}$ Department of Neurology, Hospital of Divino Espirito Santo, Ponta Delgada, Portugal. 'Department of Clinical Genetics, Hospital of D. Estefania, Lisbon, Portugal.

\section{Authors' contributions}

CB participated in the design of the study, carried out part of the molecular analysis and drafted the manuscript. CS, PR, TC, and MR participated in the molecular analysis. PC have collected part of the clinical data and contributed to draft the manuscript. TK and JV were involved in the sampling process and in the collection of the clinical data. PH participated in the design and discussion of the study. ML participated in the design and coordination of the study, and helped to draft the manuscript. All authors read and approved the final manuscript.

\section{Competing interests}

The authors declare that they have no competing interests.

Received: 5 May 2011 Accepted: 24 October 2011

Published: 24 October 2011

\section{References}

1. Schols L, Peters S, Szymanski S, Kruger R, Lange S, Hardt C, Riess O, Przuntek H: Extrapyramidal motor signs in degenerative ataxias. Arch Neurol 2000, 57(10):1495-1500.

2. Coutinho P: Doença de Machado-Joseph: Tentativa de definição. PhD Dissertation, Instituto de Ciências Biomédicas Abel Salazar, Porto; 1992.

3. Bettencourt C, Lima M: Machado-Joseph Disease: from first descriptions to new perspectives. Orphanet I Rare Dis 2011, 6:35.

4. Tuite PJ, Rogaeva EA, St George-Hyslop PH, Lang AE: Dopa-responsive parkinsonism phenotype of Machado-Joseph disease: confirmation of 14q CAG expansion. Ann Neurol 1995, 38(4):684-687.

5. Gwinn-Hardy K, Singleton A, O'Suilleabhain P, Boss M, Nicholl D, Adam A, Hussey J, Critchley P, Hardy J, Farrer M: Spinocerebellar ataxia type 3 phenotypically resembling parkinson disease in a black family. Arch Neurol 2001, 58(2):296-299.

6. Buhmann C, Bussopulos A, Oechsner M: Dopaminergic response in Parkinsonian phenotype of Machado-Joseph disease. Mov Disord 2003, 18(2):219-221.

7. Subramony SH, Hernandez D, Adam A, Smith-Jefferson S, Hussey J, GwinnHardy K, Lynch T, McDaniel O, Hardy J, Farrer M, et al: Ethnic differences in the expression of neurodegenerative disease: Machado-Joseph disease in Africans and Caucasians. Mov Disord 2002, 17(5):1068-1071.

8. Huang X, Chen PC, Poole C: APOE-[epsilon]2 allele associated with higher prevalence of sporadic Parkinson disease. Neurology 2004, 62(12):2198-2202.

9. Maraganore DM, de Andrade M, Elbaz A, Farrer MJ, loannidis JP, Kruger R, Rocca WA, Schneider NK, Lesnick TG, Lincoln SJ, et al: Collaborative analysis of alpha-synuclein gene promoter variability and Parkinson disease. JAMA 2006, 296(6):661-670

10. Wider C, Wszolek ZK: Clinical genetics of Parkinson's disease and related disorders. Parkinsonism Relat Disord 2007, 13 Suppl 3:S229-232.

11. Shoffner JM, Brown MD, Torroni A, Lott MT, Cabell MF, Mirra SS, Beal MF, Yang CC, Gearing M, Salvo R, et al: Mitochondrial DNA variants observed in Alzheimer disease and Parkinson disease patients. Genomics 1993, 17(1):171-184.

12. Bettencourt C, Fialho RN, Santos C, Montiel R, Bruges-Armas J, Maciel P, Lima M: Segregation distortion of wild-type alleles at the MachadoJoseph disease locus: a study in normal families from the Azores islands (Portugal). J Hum Genet 2008, 53(4):333-339.

13. Djarmati A, Guzvic M, Grunewald A, Lang AE, Pramstaller PP, Simon DK, Kaindl AM, Vieregge P, Nygren AO, Beetz C, et al: Rapid and reliable detection of exon rearrangements in various movement disorders genes by multiplex ligation-dependent probe amplification. Mov Disord 2007, 22(12):1708-1714. 
14. Bettencourt C, Montiel R, Santos C, Pavao ML, Viegas-Crespo AM, Lopes PA, Lima M: Polymorphism of the APOE locus in the Azores Islands (Portugal). Hum Biol 2006, 78(4):509-512.

15. Santos C, Lima M, Montiel R, Angles N, Pires L, Abade A, Aluja MP: Genetic structure and origin of peopling in the Azores islands (Portugal): the view from mtDNA. Ann Hum Genet 2003, 67(Pt 5):433-456.

16. Ramos A, Santos C, Alvarez L, Nogues R, Aluja MP: Human mitochondrial DNA complete amplification and sequencing: a new validated primer set that prevents nuclear DNA sequences of mitochondrial origin coamplification. Electrophoresis 2009, 30(9):1587-1593.

17. Bettencourt C, Santos C, Montiel R, Kay T, Vasconcelos J, Maciel P, Lima M: The (CAG)n tract of Machado-Joseph Disease gene (ATXN3): a comparison between DNA and mRNA in patients and controls. Eur J Hum Genet 2010, 18(5):621-623.

18. Macedo MG, Verbaan D, Fang $Y$, van Rooden $S M$, Visser M, Anar $B$, Uras $A$, Groen JL, Rizzu P, van Hilten JJ, et al: Genotypic and phenotypic characteristics of Dutch patients with early onset Parkinson's disease. Mov Disord 2009, 24(2):196-203.

19. Eerola J, Hernandez D, Launes J, Hellstrom O, Hague S, Gulick C, Johnson J, Peuralinna T, Hardy J, Tienari PJ, et al: Assessment of a DJ-1 (PARK7) polymorphism in Finnish PD. Neurology 2003, 61(7):1000-1002.

20. Morris CM, O'Brien KK, Gibson AM, Hardy JA, Singleton AB: Polymorphism in the human DJ-1 gene is not associated with sporadic dementia with Lewy bodies or Parkinson's disease. Neurosci Lett 2003, 352(2):151-153.

21. De Marco EV, Annesi G, Tarantino P, Nicoletti G, Civitelli D, Messina D, Annesi F, Arabia G, Salsone M, Condino F, et al: DJ-1 is a Parkinson's disease susceptibility gene in southern Italy. Clin Genet 2010, 77(2):183-188.

22. Zareparsi S, Camicioli R, Sexton G, Bird T, Swanson P, Kaye J, Nutt J, Payami H: Age at onset of Parkinson disease and apolipoprotein E genotypes. Am J Med Genet 2002, 107(2):156-161.

\section{Pre-publication history}

The pre-publication history for this paper can be accessed here: http://www.biomedcentral.com/1471-2377/11/131/prepub
doi:10.1186/1471-2377-11-131
Cite this article as: Bettencourt et al:: Parkinsonian phenotype in
Machado-Joseph disease (MJD/SCA3): a two-case report. BMC Neurology 2011 11:131.

\section{Submit your next manuscript to BioMed Central and take full advantage of:}

- Convenient online submission

- Thorough peer review

- No space constraints or color figure charges

- Immediate publication on acceptance

- Inclusion in PubMed, CAS, Scopus and Google Scholar

- Research which is freely available for redistribution

Submit your manuscript at www.biomedcentral.com/submit 